\title{
Resistance Measured by Airflow Perturbation Compared with Standard Pulmonary Function Measures"
}

\author{
Tania Haque ${ }^{1}$, Jafar Vossoughi ${ }^{2}$, Arthur T. Johnson ${ }^{3}$, Wanda Bell-Farrell, \\ Thomas Fitzgerald $^{1}$, Steven M. Scharf ${ }^{1 \#}$ \\ ${ }^{1}$ University of Maryland, Baltimore, USA \\ ${ }^{2}$ Engineering and Scientific Research Associates, Olney, USA \\ ${ }^{3}$ Fischell Department of Bioengineering University of Maryland, College Park, USA \\ Email: " sscharf@medicine.umaryland.edu
}

Received March 5, 2013; revised April 5, 2013; accepted April 13, 2013

Copyright (C) 2013 Tania Haque et al. This is an open access article distributed under the Creative Commons Attribution License, which permits unrestricted use, distribution, and reproduction in any medium, provided the original work is properly cited.

\begin{abstract}
Background: Routine lung function testing requires expensive equipment, or requires maximum expiratory effort. The airflow perturbation device (APD) is a light handheld device, allowing for serial measures of respiratory resistance noninvasively and effortlessly. Methods: In a convenience sample of 398 patients undergoing pulmonary function testing, we compared routine spirometric indices (forced expired volume in 1 second $\left(\mathrm{FEV}_{1}\right)$, peak expiratory flow $(\mathrm{PEF})$ ), and airways resistance (Raw-272 patients), to measures of respiratory resistance measured with the APD including inspiratory (IR), expiratory (ER) and averaged (AR) resistance. Results: Measures of lung function were significantly correlated $(\mathrm{p}<0.001)$. On regression analysis, between $7 \%-17 \%$ of the variance $\left(\mathrm{R}^{2}\right)$ for FEV $\mathrm{F}_{1}$, PEF, and Raw was explained by APD measurements. Approximately $2 / 3$ of the variance in $\mathrm{FEV}_{1}$ was explained by PEF measurements. Conclusions: APD measurements of lung function correlate with conventional measures. Future studies should be directed at exploring the use of the APD device in serial measures of lung function in patients with lung disease.
\end{abstract}

Keywords: Airflow Perturbation Device; Pulmonary Function; Forced Expired Volume in 1 Second; Peak Expiratory Flow; Airway Resistance

\section{Introduction}

Airway resistance is a commonly used measurement of lung function in a variety of respiratory disorders. Resistance measurement is also useful in evaluating respiratory effects of exposure to bronchoconstrictive or bronchodilatory drugs as well as to airborne pollutants.

Whole-body plethysmography is commonly used to measure airways resistance [1]. This technique requires coordinated breathing maneuvers coached by a skilled technician and a large non-portable and expensive apparatus. Another technique for measurement of pulmonary resistance (airways resistance and lung tissue resistance) is the technique of von Niergard and Wirz [2]. However, this technique necessitates the subject swallowing an uncomfortable esophageal balloon. Finally, forced oscillation, originally designed to measure respiratory impedance during tidal breathing [3] has been shown to be sensitive to changes in airways resistance [4]. For this tech-

*Funding: NIH NHLBI: 44HL078055.

\#Corresponding author. nique, sinusoidal oscillations of pressure are superimposed on tidal breathing. From the ratio of pressure changes to flow changes and the phase angles between them, impedance is calculated [4]. However, forced oscillation requires expensive equipment and is only suitable in the pulmonary function laboratory. In the clinical setting, total respiratory resistance is usually assessed indirectly using spirometric indices such as forced expired volume in one second $\left(\mathrm{FEV}_{1}\right)$ or peak expiratory flow (PEF), the latter often used at home. However, spirometric techniques require forced exhalation, require some patient training, and may be difficult or stressful for some patients to perform. Thus, most techniques for measurement of pulmonary resistance require either skilled cooperation on the part of the subject and/or specialized expensive equipment found in pulmonary function laboratories and are not suitable for home measurement.

The airflow perturbation device (APD—see Figure 1) is a variant of the forced oscillation technique suitable for use in settings outside the pulmonary function laboratory 


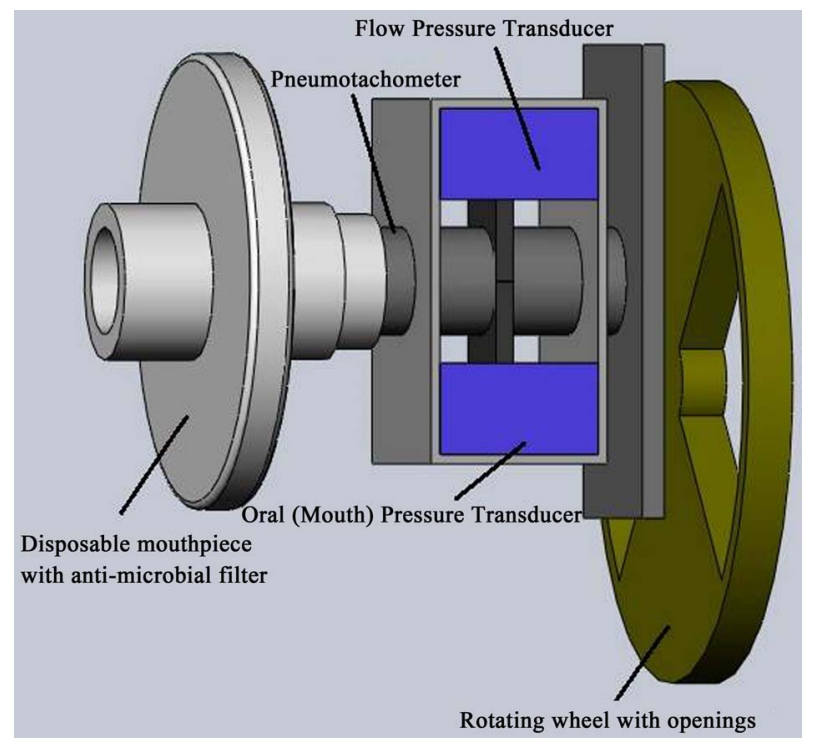

Figure 1. Schematic diagram of the APD showing the Pneumotach to measure flow rate, the pressure transducer to measure mouth pressure, and the rotating wheel to perturb airflow.

[5-7]. This lightweight, handheld, noninvasive, portable and fast device measures total respiratory resistance during quiet tidal breathing, without the need for special breathing maneuvers. The APD has been shown to measure total respiratory resistance from the mouth to the surface of the chest wall [6,7]; it thus includes airways, lung tissue, and chest wall resistance components. A segmented wheel rotating in the air pathway from the mouth causes changes at $10 \mathrm{~Hz}$ in both airflow and mouth pressure. When airflow diminishes, mouth pressure increases and vice versa. From the ratio of the amplitudes of pressure and flow perturbations, total respiratory resistance can be calculated. The APD separates respiratory resistance during inhalation from that during exhalation. This feature can be of importance for diagnosis of particular respiratory pathologies-e.g. exercise-induced paradoxical vocal fold motion that primarily affects the inspiratory phase. Additionally, the APD is small and portable, thus making it suitable for use away from the health care facility (Figure 2).

The APD device and the principles behind it have been described in detail elsewhere [5-9]. Coursey et al. [8] showed that APD derived measurements of respiratory resistance reflected changes in added resistances at least as well as classic measurements of pulmonary resistance using the esophageal balloon [2]. APD measured respiratory resistance was not significantly different from pulmonary resistance measured using the esophageal balloon. In fact, with added external resistance, the differences between APD and pulmonary resistance decreased. These authors also demonstrated that expiratory isovolume pressure-flow curves could reliably be ob-

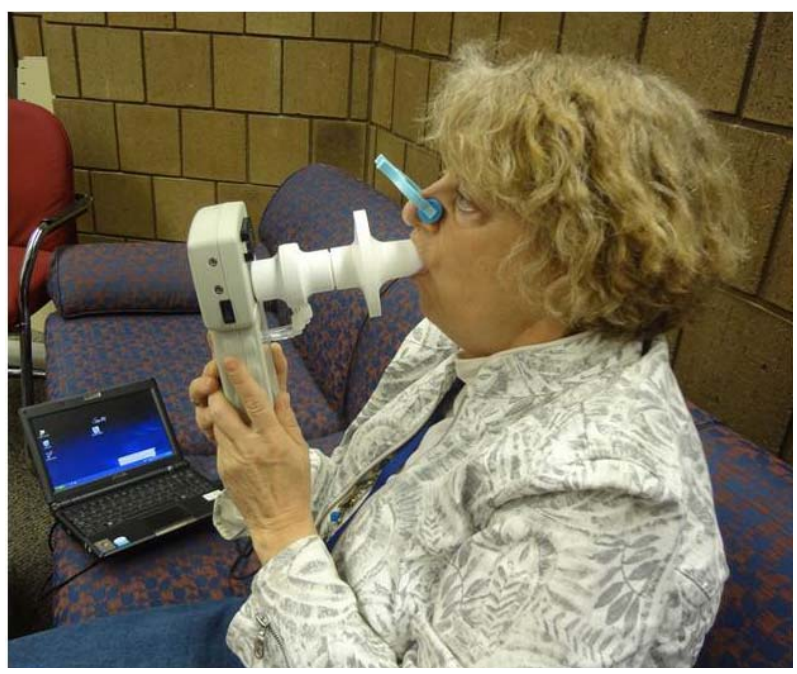

Figure 2. Subject using the hand held APD. This device was connected to a laptop computer for data recording. However, this is not required for use. All values are displayed on a screen in the field of vision.

tained with the APD technique [9].

The APD offers a number of potential advantages for the frequent following of lung function in patients with pulmonary disease. First, it requires no cumbersome equipment. Second, it requires no complicated maneuvers like panting or forced expiration. Finally, it does not require a forced expiration like $\mathrm{FEV}_{1}$ or PEF. Thus APD measurement would seem to be ideal to use as an out of hospital assessment of lung function.

The current study is designed to compare measurements of respiratory resistance using the APD with commonly used indices of lung function, based on spirometry or body plethysmography, in adults referred to the pulmonary function laboratory for evaluation of lung function. We hypothesized that APD measurements of resistance would be significantly correlated with standard laboratory measures of lung function.

\section{Methods}

The protocol was approved by the University of Maryland Institutional Review Board. Inclusion criteria included: age $\geq 18$, and willingness and ability to sign informed consent in the English language. Patients were excluded if they appeared to have an unstable pulmonary condition requiring referral to urgent care. A convenience sample of 398 patients, aged 18 to 88 , with a variety of pulmonary complaints, referred to the pulmonary function laboratory for routine pulmonary function testing by their providers was studied. All subjects underwent spirometric testing. In 272 , body plethysmography was also performed allowing for measurements of lung volume and airways resistance [10], and in 23 spirmetry and APD measures were repeated following bronchodi- 
lator. Since the laboratory performed only those tests requested by the referring provider, we could not add to these numbers. Following measurements of lung function as ordered by their provider, subjects were asked to quietly breathe through the airflow perturbation device for one minute in the sitting position. A nose clip was used to obstruct nasal breathing. In some cases, APD measurements were performed twice on the same day: following spirometry before bronchodilator and following spirometry after bronchodilator.

Spirometry and body plethysmography were performed using a SensorMedics Viasys system according to the standards set out by the American Thoracic Society/European Respiratory Society [11,12]. Spirometry yielded values for $\mathrm{FEV}_{1}$, forced vital capacity (FVC) and PEF. Body plethysmography yielded values for lung volumes including functional residual capacity (FRC), airways resistance (Raw), and specific airways conductance $(\mathrm{sGaw}=1 / \mathrm{Raw} / \mathrm{FRC})$. Predicted values for spirometry and body plethysmograph measurements were generated using standard published equations $[13,14]$. For APD measurements, we used a lightweight handheld APD device (see Figure 2). Patients breathed normally for 1 minute through the APD while their nostrils were blocked with a nose clip. No special breathing maneuvers were required. APD measurements yielded values for inspiratory (IR) and expiratory resistance (ER) as well as respiratory resistance averaged over the entire respiratory cycle (AR).

\section{Data Analysis}

Data were collected and collated. Central tendency was estimated as the mean and variability as standard deviation as all data were normally distributed (Shapiro-Wilk test). Differences between multiple means were assessed using one-way analysis of variance for repeated measures. If significance was found, we used post-hoc testing (Neuman-Keuls) to determine the source of the significance. Associations between variables were assessed using the Least-Squares technique and Pearson coefficients were calculated. For most analyses, linear regression yielded the greatest correlation. SigmaPlot 12.2 (Systat software, Inc.-Chicago, Ill) was used to perform all statistical analyses. The null hypothesis was rejected at the $5 \%$ level.

\section{Results}

The sample was composed of $46 \%$ males and included 52\% Caucasian, 44\% African American and 3\% from other ethnicities. One-hundred and nineteen were former or current smokers (mean smoking history $=26.2 \pm 22.6$ pack-years). Table 1 shows anthropomorphic data as well as average prebronchodilator lung function meas-
Table 1. Anthropometric data and prebronchodilator measures of lung function.

\begin{tabular}{|c|c|c|}
\hline & Mean & Std Deviation \\
\hline Age & 55.5 & 14.7 \\
\hline $\operatorname{BMI}\left(\mathrm{kg} / \mathrm{m}^{2}\right)$ & 31.7 & 19.5 \\
\hline $\mathrm{IR}\left(\mathrm{cm} \mathrm{H}_{2} \mathrm{O} / \mathrm{L} / \mathrm{sec}\right)$ & 2.9 & 1.0 \\
\hline $\mathrm{ER}\left(\mathrm{cm} \mathrm{H}_{2} \mathrm{O} / \mathrm{L} / \mathrm{sec}\right)$ & 3.1 & 1.2 \\
\hline $\mathrm{AR}\left(\mathrm{cm} \mathrm{H} \mathrm{H}_{2} \mathrm{O} / \mathrm{L} / \mathrm{sec}\right)$ & 3.0 & 1.0 \\
\hline $\mathrm{FEV}_{1}(\mathrm{~L})$ & 2.2 & 0.9 \\
\hline $\mathrm{FEV}_{1}(\%$ predicted $)$ & 77.7 & 24.3 \\
\hline FVC (L) & 3.0 & 1.1 \\
\hline FVC $(\%$ predicted $)$ & 79.2 & 20.5 \\
\hline $\mathrm{FEV}_{1} / \mathrm{FVC} \%$ & 71.9 & 14.2 \\
\hline $\operatorname{Raw}\left(\mathrm{cm} \mathrm{H}_{2} \mathrm{O} / \mathrm{L} / \mathrm{sec}\right)$ & 3.3 & 2.8 \\
\hline sGaw (L/sec/cm H $\left.\mathrm{H}_{2} \mathrm{O} / \mathrm{L}\right)$ & 0.1 & 0.1 \\
\hline $\mathrm{FEF}_{25}(\mathrm{~L} / \mathrm{sec})$ & 1.9 & 1.2 \\
\hline $\mathrm{FEF}_{25}(\%$ predicted $)$ & 62.5 & 35.3 \\
\hline $\mathrm{PEF}(\mathrm{L} / \mathrm{sec})$ & 6.1 & 4.2 \\
\hline PEF (\% predicted) & 71.9 & 14.1 \\
\hline
\end{tabular}

$\mathrm{BMI}=$ body mass index; $\mathrm{IR}=$ inspiratory resistance from the $\mathrm{APD} ; \mathrm{ER}=$ expiratory resistance form the APD; $\mathrm{AR}=$ resistance averaged over inspiration and expiration from the $\mathrm{APD} ; \mathrm{FEV}_{1}=$ forced expired volume in $1 \mathrm{sec}$ tion; $\mathrm{FVC}=$ forced vital capacity; $\mathrm{FEV}_{1} / \mathrm{FVC} \%=$ the ratio of $\mathrm{FEV}_{1}$ to $\mathrm{FVC}$ expressed as a percent; Raw = airway resistance; $\mathrm{sGaw}=$ specific conductance; $\mathrm{FEF}_{25}=$ forced expiratory flow at $25 \%$ of the vital capacity; $\mathrm{PEF}=$ peak expiratory flow.

urements. There were no significant differences between mean Raw and AR, IR or ER. A total of $137 / 398$ patients had "obstructive" physiology, defined as $\mathrm{FEV}_{1} / \mathrm{FVC}$ less than $70 \%$. A total of $126 / 398$ patients had "restrictive" physiology, defined as $\mathrm{FEV}_{1} / \mathrm{FVC}>70 \%$ and $\mathrm{FVC}<$ $80 \%$ predicted.

Table 2 shows correlations between the different variable measured. All correlations were significant $(p<$ $0.001)$. Also shown are the values for $R^{2}$. This is the proportion of the variance in the dependent variable explained by the independent variable. For correlations between APD measurements and either $\mathrm{FEV}_{1}$ or PEF, $\mathrm{R}^{2}$ (percent of explained variance) was in the $7 \%-12 \%$ range. For the correlation between APD measurements and Raw (plethysmograph) $\mathrm{R}^{2}$ was $15 \%$ - 17\%. Also shown in Table 2 are correlations between the APD measurements AR, IR and ER. As expected, these indicated a tight correlation between the various APD measures of respiratory resistance, with the variability in one measure accounting for $68 \%-92 \%$ of the variance in the other. Figure 3 shows the regression of $A R$ on $\mathrm{FEV}_{1}$. When we compared $\mathrm{FEV}_{1}$ (an expiratory maneuver), to ER a similar regression was found (Figure 4). Correlations between $\mathrm{FEV}_{1}$ and $\mathrm{APD}$ measurements and $\mathrm{PEF}$ and APD measurements were in the expected direction, 
Table 2. Correlation coefficients between different measures of lung function were calculated and shown below.

\begin{tabular}{|c|c|c|c|c|c|}
\hline & $\begin{array}{l}\text { PEF } \\
(\mathrm{L} / \mathrm{sec})\end{array}$ & $\begin{array}{c}\text { Raw } \\
(\mathrm{cm} \\
\left.\mathrm{H}_{2} \mathrm{O} / \mathrm{L} / \mathrm{s}\right)\end{array}$ & $\begin{array}{c}\text { IR } \\
(\mathrm{cm} \\
\left.\mathrm{H}_{2} \mathrm{O} / \mathrm{L} / \mathrm{s}\right)\end{array}$ & $\begin{array}{c}\begin{array}{c}\text { ER } \\
(\mathrm{cm}\end{array} \\
\left.\mathrm{H}_{2} \mathrm{O} / \mathrm{L} / \mathrm{s}\right)\end{array}$ & $\begin{array}{c}\mathrm{AR} \\
(\mathrm{cm} \\
\left.\mathrm{H}_{2} \mathrm{O} / \mathrm{L} / \mathrm{s}\right)\end{array}$ \\
\hline $\operatorname{FEV}_{1}(\mathrm{~L})$ & $\begin{array}{c}0.82 \\
\mathrm{R}^{2}=0.68\end{array}$ & $\begin{array}{c}-0.44 \\
\mathrm{R}^{2}=0.19\end{array}$ & $\begin{array}{c}-0.31 \\
\mathrm{R}^{2}=0.10\end{array}$ & $\begin{array}{c}-0.35 \\
\mathrm{R}^{2}=0.12\end{array}$ & $\begin{array}{c}-0.35 \\
\mathrm{R}^{2}=0.12\end{array}$ \\
\hline $\begin{array}{c}\text { PEF } \\
(\mathrm{L} / \mathrm{sec})\end{array}$ & & $\begin{array}{c}-0.42 \\
\mathrm{R}^{2}=0.18\end{array}$ & $\begin{array}{c}-0.20 \\
\mathrm{R}^{2}=0.08\end{array}$ & $\begin{array}{c}-0.31 \\
\mathrm{R}^{2}=0.09\end{array}$ & $\begin{array}{c}-0.31 \\
\mathrm{R}^{2}=0.07\end{array}$ \\
\hline 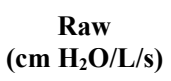 & & & $\begin{array}{c}0.39 \\
\mathrm{R}^{2}=0.15\end{array}$ & $\begin{array}{c}0.39 \\
\mathrm{R}^{2}=0.153\end{array}$ & $\begin{array}{c}0.41 \\
\mathrm{R}^{2}=0.17\end{array}$ \\
\hline $\begin{array}{c}\text { IR } \\
\left.\text { (cm } \mathrm{H}_{2} \mathrm{O} / \mathrm{L} / \mathrm{s}\right)\end{array}$ & & & & $\begin{array}{c}0.83 \\
\mathrm{R}^{2}=0.69\end{array}$ & $\begin{array}{c}0.95 \\
\mathrm{R}^{2}=0.90\end{array}$ \\
\hline $\begin{array}{c}\text { ER } \\
\left(\mathrm{cm} \mathrm{H} \mathrm{H}_{2} \mathrm{O} / \mathrm{L} / \mathrm{s}\right)\end{array}$ & & & & & $\begin{array}{c}0.96 \\
\mathrm{R}^{2}=0.92\end{array}$ \\
\hline
\end{tabular}

For abbreviations see previous table. All correlations were significant to the $\mathrm{p}<0.001$ level.

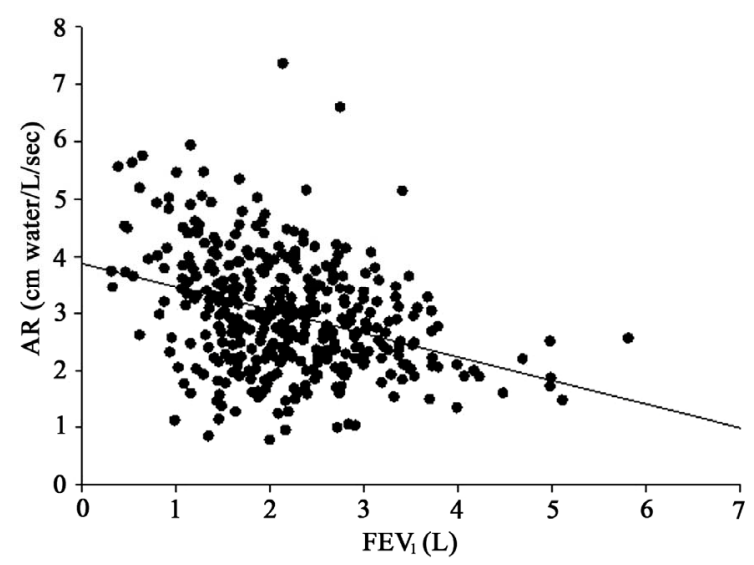

Figure 3. Regression of AR on $\mathrm{FEV}_{1} ; \mathrm{AR}=3.883-(0.412 \times$ $\left.\mathrm{FEV}_{1}\right) ; \mathrm{R}^{2}=0.124 ; \mathrm{p}<0.001$.

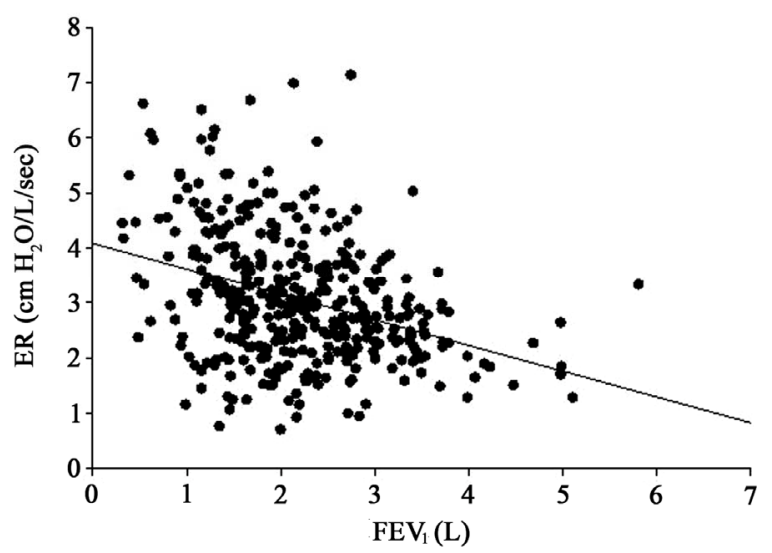

Figure 4. Regression of ER on $F E V_{1} ; E R=4.085-(0.465 \times$ $\left.\mathrm{FEV}_{1}\right) ; \mathrm{R}^{2}=0.123 ; \mathrm{p}<0.001$.

i.e. as $\mathrm{FEV}_{1}$ or PEF increased (improved function), APD resistance decreased. Figure 5 shows the regression of AR on Raw (all measured prebronchodilator). While the correlation was significant with similar correlation coefficients as in Figures 3 and 4, it was clear that there was

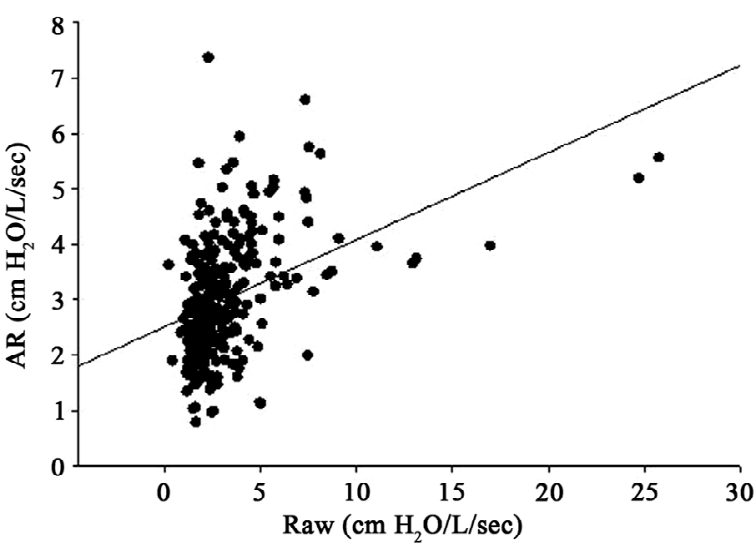

Figure 5. Regression of AR on Raw; AR $1=2.515+(0.157 \times$ Raw); $\mathbf{R}^{2}=0.167 ; \mathrm{p}<0.001$.

a great degree of leverage in points towards the extremes of each. The correlation between 2 commonly used indices of lung function, $\mathrm{FEV}_{1}$ and PEF (Table 2) showed that some $2 / 3$ of the variance of one was explained by the other.

Finally, we compared bronchodilator associated changes in indices of lung function between $\mathrm{FEV}_{1}$ and APD measurements. The mean change in $\mathrm{FEV}_{1}$ with bronchodilator in the 28 patients in whom data were obtained pre and post bronchodilator was relatively small: $0.10 \pm$ $0.23 \mathrm{~L}$. The correlations between changes in APD measurements and $\mathrm{FEV}_{1}$ were not significant: For ER: $\triangle \mathrm{ER}=$ $0.0486-\left(0.264 \times \Delta \mathrm{FEV}_{1}\right), \mathrm{R}=0.103, \mathrm{NS}$; For AR: $\triangle \mathrm{AR}$ $=0.00279-\left(0.140 \times \Delta \mathrm{FEV}_{1}\right), \mathrm{R}=0.063$; For IR: $\Delta \mathrm{IR}=$ $0.0257-\left(0.416 \times \Delta \mathrm{FEV}_{1}\right), \mathrm{R}=0.178$.

\section{Discussion}

We compared measurements commonly used to assess lung function in the pulmonary function laboratory with those obtained using the APD. While significant correlations were found, only $7 \%-17 \%$ of the variance in APD measurements was explained by $\mathrm{FEV}_{1}$, PEF or Raw. Further, there was no correlation between the change in $\mathrm{FEV}_{1}$ and APD measurements with bronchodilator. In the ensuing discussion we review these findings in the light of the current available literature.

To our knowledge this is the largest group of subjects in which changes in APD and other assessments of lung function were compared. Further, the other studies cited included normal healthy subjects. The current study includes unselected patients referred to the pulmonary function lab for a variety of indications as determined by their attending providers.

As shown by the figures and Table 2, the correlations with $\mathrm{FEV}_{1}$, PEF, and Raw, although going in the expected directions, and statistically significant, are not tight, with only $7 \%-17 \%$ of the variance of one being explained by the other. By contrast, the correlation be- 
tween $\mathrm{FEV}_{1}$ and $\mathrm{PEF}$, that are forced expiratory maneuvers, was excellent, with some $2 / 3$ of the variance in one explained by the other.

It is important to bear in mind that the various measures of pulmonary function actually measure different aspects of respiratory mechanics. $\mathrm{FEV}_{1}$ and PEF are certainly responsive to changes in airways resistance; however, they are also very dependent on patient effort. Raw, measured in the body plethysmograph, is sensitive to changes in flow-resistance of the airways, but excludes lung and chest wall tissue resistance. The APD measures total respiratory resistance, and includes a large component of upper airways resistance (see [8]). The most practical use for the APD would likely be to follow patients with lung disease serially at home given the ease of use and low cost of this device. We had hoped that the measurement of serial function before and after bronchodilator would simulate serial measurements for standard spirometry compared with APD. Unfortunately, few patients had bronchodilator studies ordered, and the overall change in $\mathrm{FEV}_{1}$ with bronchodilator was small (approximately $100 \mathrm{cc}$ ). Finally, in a recent study [15], the intrasubject variability of APD measurements was assessed. It was found that the largest portion of the variability of measurements was in fact due to changes within the subject and not to changes within the APD, strengthening our argument that the device would be most useful for serial measurements in patients with lung disease.

In sum, there are significant correlations between APD derived measures of respiratory resistance and measures derived from standard pulmonary function testing. The variance explained was less than that between commonly used measures of pulmonary function. Studies should be directed at the evaluation of efficacy of serial measurements over time in patients with respiratory disease.

\section{REFERENCES}

[1] A. M. Dubois, S. Y. Botelho and J. H. Comroe Jr., "A New Method for Measuring Airway Resistance in Man Using a Body Plethysmograph: Values in Normal Subjects and in Patients with Respiratory Disease," Journal of Clinical Investigation, Vol. 35, No. 3, 1956, pp. 327335. doi:10.1172/JCI103282

[2] K. Von Neergard and K. Wirz, "Die Messimg. Der Stromungwiderstande in den Atemwegen des Menschen Insbespondere bie Asthma und Emphysema," Zeitschrift fur Klinische Medizine, Vol. 105, 1927, pp. 51-82.

[3] A. M. DuBois, A. W. Brody, D. H. Lewis and B. F. Burgess, "Oscillation Mechanics of Lungs and Chest in Man," Journal of Applied Physiology, Vol. 8, No. 6, 1956, pp. 587-594.

[4] H. J. Smith, P. Reinhold and M. D. Goldman, "Forced Oscillation Technique and Impulse Oscillometry," European Respiratory Journal, Vol. 31, 2005, pp. 72-105.
[5] A. T. Johnson, C.-S. Lin and J. N. Hochheimer, "Airflow Perturbation Device for Measuring Airway Resistance of Humans and Animals," IEEE Transactions on Biomedical Engineering, Vol. 31, No. 9, 1984, pp. 622-626. doi:10.1109/TBME.1984.325306

[6] C. G. Lausted and A. T. Johnson, "Airflow Perturbation Device for Measureing Human Respiratory Resistance," Proceedings of the IEEE $24^{\text {th }}$ Annual Northeast Conference, 9-10 April 1998, pp. 97-99.

[7] A. T. Johnson and M. S. Sahota, "Validation of Airflow Perturbation Device Resistance Measurements in Excised Sheep Lungs," Physiological Measurement, Vol. 25, No. 5, 2004, pp. 679-690. doi:10.1088/0967-3334/25/3/008

[8] D. C. Coursey, S. M. Scharf and A. T. Johnson, "Comparing Pulmonary Resistance Measured with an Esophageal Balloon to Resistance and Measurements with an Airflow Perturbation Device," Physiological Measurement, Vol. 31, No. 7, 2010, pp. 921-934. doi:10.1088/0967-3334/31/7/004

[9] D. C. Coursey, S. M. Scharf and A. T. Johnson, "Comparison of the Expiratory Isovolume Pressure Flow Relationship Generated with Stop-Flow and Esophageal Balloon Methods," Respiratory Care, Vol. 56, No. 7, 2011, pp. 969-975. doi:10.4187/respcare.01037

[10] N. K. Silverman, A. T. Johnson, W. H. Scott and F. C. Koh, "Exercise-Induced Respiratory Resistance Changes as Measured with the Airflow Perturbation Device," Physiological Measurement, Vol. 26, No. 1, 2005, pp. 2938. doi:10.1088/0967-3334/26/1/003

[11] M. R. Miller, J. Hankinson, V. Brusasco, F. Burgos, R. Casaburi, A. Coates, R. Crapo, P. Enright, C. P. M. van der Grinten, P. Gustafsson, R. Jensen, D. C. Johnson, N. MacIntyre, R. McKay, D. Navajas, O. F. Pedersen, R. Pellegrino, G. Viegi and J. Wanger, "Standardisation of Lung Function Testing: Standardisation of Spirometry," European Respiratory Journal, Vol. 26, No. 2, 2005, pp. 319-338. doi:10.1183/09031936.05.00034805

[12] J. Wanger, J. L. Clausen, A. Coates, O. F. Pedersen, V. Brusasco, F. Burgos, R. Casaburi, R. Crapo, P. Enright, C. P. M. van der Grinten, P. Gustafsson, J. Hankinson, R. Jensen, D. Johnson, N. MacIntyre, R. McKay, M. R. Miller, D. Navajas, R. Pellegrino and G. Viegi, "Standardisation of the Measurement of Lung Volumes," European Respiratory Journal, Vol. 26, No. 3, 2005, pp. 511-522. doi:10.1183/09031936.05.00035005

[13] J. F. Morris, A. Koski and L. C. Johnson, "Spirometric Standards for Healthy Non-Smoking Adults," American Review of Respiratory Disease, Vol. 103, 1971, pp. 5767.

[14] R. O. Crapo, A. H. Morris, P. D. Clayton and C. R. Nixon, "Lung Volumes in Healthy Nonsmoking Adults," Bulletin Européen de Physiopathologie Respiratoire, Vol. 18, No. 3, 1982, pp. 419-425.

[15] A. T. Johnson, S. C. Jones, J. J. Pan and J. Vosoughi, "Variation of Respiratory Resistance Suggests Optimization of Airway Caliber," IEEE Transactions on Biomedical Engineering, Vol. 59, No. 8, 2012, pp. 2355-2361. doi:10.1109/TBME.2012.2204055 